\title{
METHODOLOGY OF DETERMINING POINTS OF EFFECTIVE COMPENSATION OF REACTIVE CAPACITY IN AIR NETWORKS 0.4 KV
}

\author{
Vera Sidorova, Elena Rokina \\ Mari State University, Russia \\ veranig@yandex.ru
}

\begin{abstract}
The losses of active power are directly proportional to the active power in square and the active resistance of the line, inversely proportional to the square of the product of the voltage and the power factor. The increase in voltage in the line is limited by the maximum permissible voltage value in accordance with the "Norms for the quality of electricity in general-purpose power supply systems". Replacing the wires of the power line can be economically inexpedient, since a large part of them in Russia have a long duration. Obviously, it is possible to effectively reduce power losses by increasing the power factor. In this case, an increase in the power factor will lead to an increase in the voltage in the line. This additional effect is often necessary due to a significant loss of voltage as a result of electricity transmission. In Russia, it is considered that the compensation of reactive power in low voltage networks is inadvisable in view of the small transmitted power and the lack of reactive power consumers. In addition, there is no information on the flows of power and voltage values of low voltage networks, which complicates the task of effective compensation of reactive power. In this paper, we present a technique for determining the points of installation of compensating devices from the point of view of economic feasibility from the data of planned measurements of power flows and stress values. In the paper, phase-by-phase compensation of reactive power is proposed. The developed technique allows to achieve the best values of power factor and voltage deviation in points on the line. In this case, several variants of distribution of compensation devices on the line can be obtained. In this case, the user can choose the best option for setting the compensating devices in terms of economic and technical capabilities.
\end{abstract}

Keywords: reactive power, compensation, voltage, power factor.

\section{Introduction}

In Russia, at present, there is a high growth in construction of the private sector, while the load of household consumers increases. As a consequence, in the $0.4 \mathrm{kV}$ electric networks, designed according to the consumption norms of the last century, there is deterioration in the values of the power factor, steady voltage deviation and other indicators of power quality. As a result of the above, the losses of electric power are sharply increased. In view of the considerable asymmetry of the load in such networks, this work proposes a phase-by-phase compensation of the reactive power directly on the line. For effective reactive power compensation (RPC) in $0.4 \mathrm{kV}$ air networks, it is necessary to determine the installation points of compensating devices in terms of economic feasibility. At the same time, such important indicators as the power factor and voltage deviation at the point of connection of consumers will be significantly improved.

The loss of electricity is directly related to the loss of active power for the transmission of electricity. These losses can be determined [1]:

$$
\Delta P=\frac{P^{2}+Q^{2}}{U^{2}} R=\frac{P^{2}\left(1+\operatorname{tg}^{2} \varphi\right)}{U^{2}} R=\frac{P^{2} R}{U^{2}} \frac{1}{\cos ^{2} \varphi},
$$

where $P, Q$-active and reactive powers transmitted on the line;

$U$ - line voltage;

$R$ - equivalent line resistance ( $R=r L, \mathrm{r}$ is the line resistivity, $L$ is the line length);

$\cos \varphi$ - power factor;

$\operatorname{tg} \varphi$ - reactive power factor in the line.

It follows from expression (1) that, if the transmitted power $P$ and the voltage $U$ in the line remain unchanged, the power losses will depend on the power factor and the length of the line $L$. In 2007, in the Russian Federation [2], the minimum reactive power factor for the connection points of the consumer to the electric network $10(6)-0.4 \mathrm{kV}$ was significantly toughened. It is established that $\cos$ $\varphi=0.944(\operatorname{tg} \varphi=0.35)$ for a $0.4 \mathrm{kV}$ network and $\cos \varphi=0.93(\operatorname{tg} \varphi=0.4)$ for a $6-20 \mathrm{kV}$ network.

In the transmission of electrical energy, there are additional voltage losses $\Delta U$, which are particularly significant in rural distribution networks. When transmitting the power $P$ and $Q$ through 
an element of the power supply system with active $R$ and reactive resistance $X$, the voltage losses will be [3]:

$$
\Delta U=\frac{P R+Q X}{U} .
$$

where $U$ - rated voltage of the network.

Additional voltage losses increase the voltage deviation at the receiver terminals from the nominal value, when the loads and network modes change. This requires increasing the power, hence, the cost of voltage regulation. Thus, the transfer of reactive power from the current distributor is economically inexpedient.

In European countries, the RPC is carried out in $0.4 \mathrm{kV}$ air networks. In this case, compensation is made by global, group compensation or individual compensation, for example [4-5]. In Russia, only global compensation or individual compensation of industrial enterprises is realized. Compensation directly on the transmission line with the prevailing load of household consumers in the network is not made. In [6], a local RPC was proposed in $0.4 \mathrm{kV}$ air networks, i.e. directly at the points of the power line, where necessary. In the same studies, the maximum power of the RPC devices was determined with their proposed distribution, which is $50 \mathrm{kVAr}$. Modern PRC devices of this power have small weight and size parameters, and with the corresponding case design they can be installed on the air line supports (masted method). The efficiency of compensation will depend on the selected points on the line for the installation of the compensating devices. Due to the lack of data on power flows and voltage values in the network, this task is currently not being solved in Russia. Therefore, in this paper, we propose an algorithm for determining the points of effective compensation, taking into account economic feasibility. Further, the authors of the work plan to create a software product based on the developed algorithm. In previous works, for example [6], studies of real air transmission lines of $0.4 \mathrm{kV}$ were carried out according to the power quality indicators. Also, the dependences of the steady-state voltage deviation, the asymmetry coefficients for the forward, reverse and zero sequence and electric power losses on the power factor in real lines of $0.4 \mathrm{kV}$ were investigated. Based on the results obtained, the algorithm proposed in this paper is developed.

\section{Methodology for determining the points of effective RPC}

When analyzing the data of planned measurements in low-voltage networks, the following results were obtained. The active and reactive phase powers transmitted along the line could have the same values.

In a significant part of the lines studied, even in the middle of the line: the value of the power factor was less than the required minimum value; the value of the zero-sequence asymmetry coefficient exceeded the maximum permissible value. In the middle of the line, the value of the zerosequence asymmetry coefficient exceeded the normally acceptable value. In connection with the foregoing, in such networks, there are significant energy losses, and earlier wear of electrical equipment.

Since the phase capacities in the same point of the line had significant differences, the calculation of the losses of active power must be carried out in phases. This can be done using expression (1), where all the quantities are phases, and carry out the summation over the phases:

$$
\Delta P=\sum_{i=1}^{n} \frac{P_{A i}^{2} R_{A i}}{U_{A i}^{2}} \frac{1}{\cos ^{2} \varphi_{A i}}+\sum_{i=1}^{n} \frac{P_{B i}^{2} R_{B i}}{U_{B i}^{2}} \frac{1}{\cos ^{2} \varphi_{B i}}+\sum_{i=1}^{n} \frac{P_{C i}^{2} R_{C i}}{U_{C i}^{2}} \frac{1}{\cos ^{2} \varphi_{C i}},
$$

where $P_{A i}, P_{B i}, P_{C i}$-phase powers of the sections of the network;

$R_{A i}, R_{B i}, R_{C i}$ - equivalent phase conductors;

$U_{A i}, U_{B i}, U_{C i}$ - phase voltages of the network sections;

$\cos \varphi_{A i}, \cos \varphi_{B i}, \cos \varphi_{C i}$ - phase power coefficients of the sections.

When calculating, it is necessary to take into account the actual values of the power factor and voltage in phases. The developed algorithm (Fig. 1) is based on the method of determining compensation points, which is described below. 

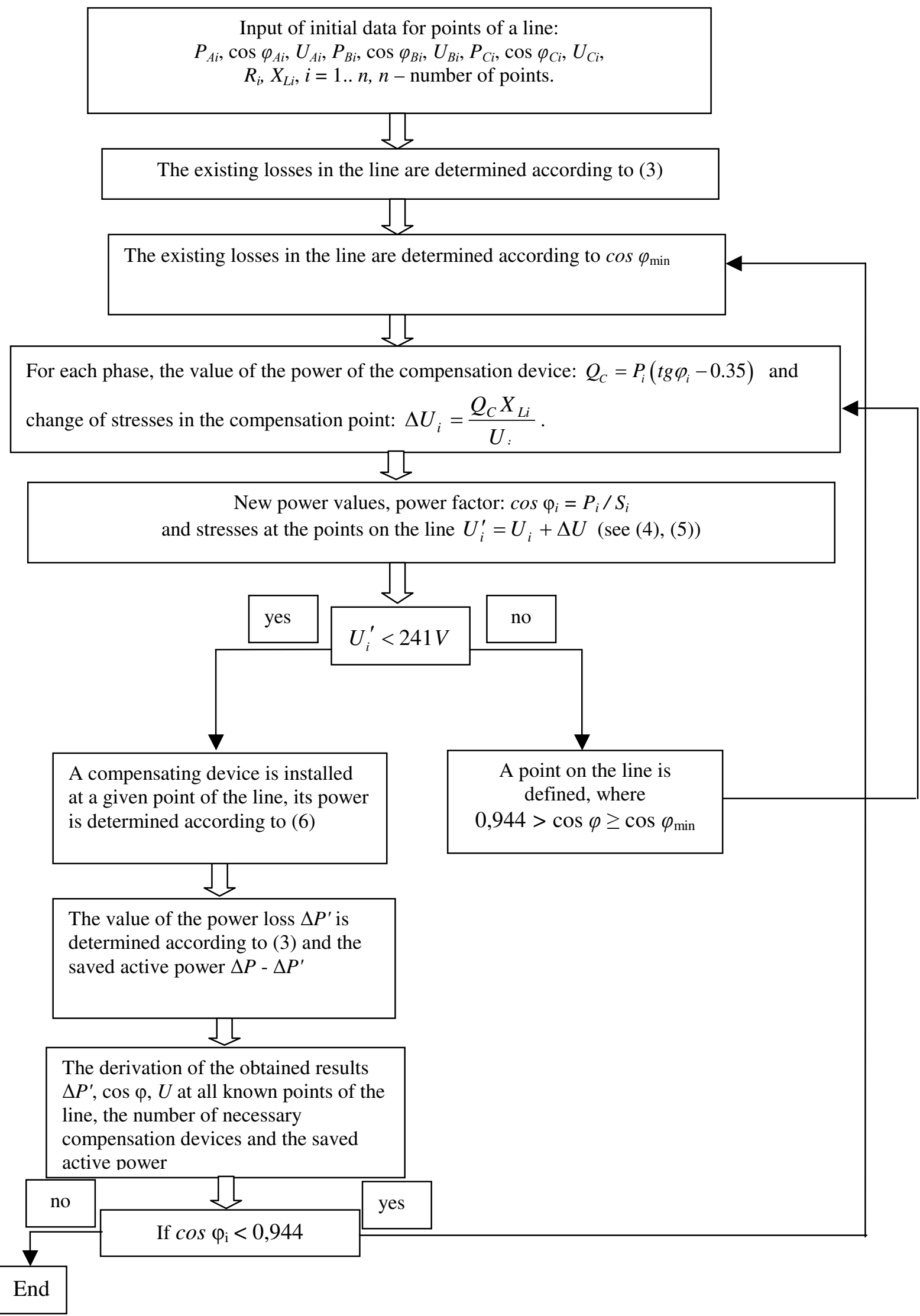

Fig. 1. Algorithm for determining effective points of RPC

First, the existing losses in the network are determined by planned or special measurements of the average phase values of the active power (during the maximum load period, at least a week), voltages 
and the power factor according to the expression (3). Then the point on the line is determined, where the smallest value of the power factor is $\cos \varphi_{\min }$. Further, the values of the phase reactive powers required for compensation before the value $\tan \varphi=0.35(\cos \varphi=0.944$ [2]) are determined, for example, according to [1]:

$$
Q_{C}=P_{i}\left(\operatorname{tg} \varphi_{i}-0.35\right) .
$$
[1]:

Also new values of voltages and capacities in each phase are determined after such compensation

$$
\begin{gathered}
Q_{i}^{\prime}=Q_{i}-Q_{C}, S_{i}^{\prime}=\sqrt{P_{i}^{2}+Q_{i}^{\prime 2}}, \\
\Delta U_{i}=\frac{Q_{C} X_{L i}}{U_{i}}, U_{i}^{\prime}=U_{i}+\Delta U_{i},
\end{gathered}
$$

where $Q^{\prime}{ }_{i}, S^{\prime}{ }_{i}$ - calculated values of reactive and apparent power, respectively;

$\Delta U_{i}-$ increase in the values of phase voltages;

$U^{\prime}{ }_{i}$ - calculated values of phase voltages, after compensation.

If, after compensation, the values of the phase voltages do not exceed the normal permissible values according to $[7 ; 8]$, then the device should be installed at this point. The required capacitor capacitance values for each phase are determined from the expression [3]:

$$
C=\frac{Q_{C}}{U^{2} \omega},
$$

where $C, Q_{C}$ and $U$ - capacitance of the capacitor bank, the reactive power determined from (4), and the voltage of the corresponding phase $\omega$ is the angular frequency of the mains voltage.

Further, the power losses after the installation of the RPM device according to (3) are determined. After that, anew is determined at which point on the line the power factor is minimum and the above algorithm is repeated. This algorithm is repeated until the power factor at all points on the line becomes greater than or equal to 0.944 . If, as a result of the calculation the value of the phase voltages exceeds normal values, another point is determined, where the power factor also has a minimum value. Network diagram of $0.4 \mathrm{kV}$ with supports is shown in Fig. 2 for explanation of power flows.

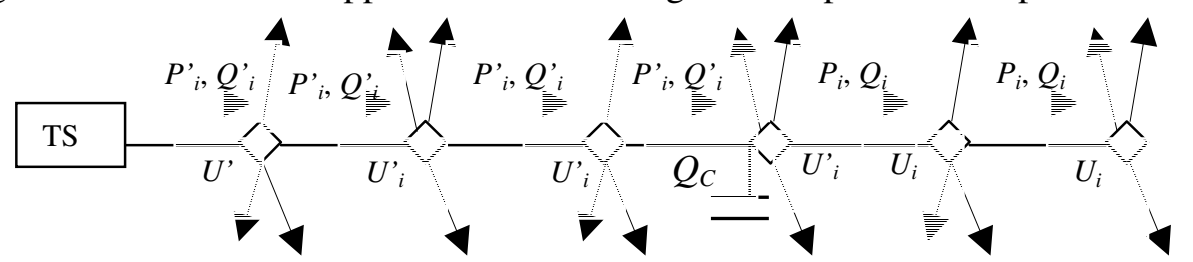

Fig. 2. Network scheme $0.4 \mathrm{kV}$ with supports, TS - transforming substation

\section{Conclusions}

In this work, a technique has been developed for determining the points of installation of PRC devices in the form of an algorithm for software. This technique will serve to reduce power losses and ensure the best values of voltages in the network. A distinctive feature of the proposed technique will be a step-by-step determination of the compensation points for the minimum value of the power factor taking into account changes in stress values due to compensation. At the same time, compensation is proposed to be carried out in phases. The authors plan to develop and create a model electric line of $0.4 \mathrm{kV}$. Then the developed program will be tested and corrected on the model line. After the adjustment, the developed software will be tested in real $0.4 \mathrm{kV}$ lines.

\section{Acknowledgement}

This work was carried out with the financial support of the grant to the winner of the AllRussian Youth Projects Competition of 2017 by the Federal Agency for Youth Affairs, the executive is Elena Rokina, the consultant is Sidorova Vera. 


\section{References}

[1] Железко Ю. С. Потери электроэнергии. Реактивная мощность. Качество электроэнергии: Руководство для практических расчетов (Loss of electricity. Reactive power. Quality of electricity: A guide for practical calculations.) Moscow: ENAS, 2009. 456 p. (In Russian).

[2] Приказ Минпромэнерго России от 22.02.2007 № 49. (The order of the Ministry of Industry and Energy of Russia of February 22, 2007. No. 49). (In Russia). [online] [16.03.2018] Available at:

http://www.consultant.ru/cons/cgi/online.cgi?base $=$ LAW; $\mathrm{n}=66814 ; \mathrm{req}=$ doc\#08390501234892 4.

[3] Карташев И.И., Тульский В.Н. и др.; под ред. Ю.В. Шарова Управление качеством электроэнергии (Electricity Quality Management) Moscow: Publishing house MEI, 2008, 354 p. (In Russian).

[4] Andrija Volkanovski1, Marko Čepin, Borut Mavko Optimization of reactive power compensation in distribution networks Elektrotehniški vestnik, Electrotechnical Review: Ljubljana, Slovenija 76(1-2), 2009, pp. 57-62

[5] Pourshafie A., Saniei M., Mortazavi S. S., Saeedian A. Optimal Compensation of Reactive Power in the Restructured Distribution Network International Scholarly and Scientific Research \& Innovation, vol 3, No 6, 2009.

[6] Карчин В.В., Сидорова В.Т., Леухин А.Н. Улучшение показателей качества электроэнергии в сельских распределительных сетях 0,4 кВ с помощью компенсации реактивной мощности (Improvement of electricity quality indicators in rural $0.4 \mathrm{kV}$ distribution networks by means of reactive power compensation) Problems of energy, 2015, No 1-2, pp. 61-67. (In Russia).

[7] ГОСТ 32144-2013 Электрическая энергия. Совместимость технических средств электромагнитная. Нормы качества электрической энергии в системах электроснабжения общего назначения (Interstate Standard GOST 32144-2013 "Electric Energy: Electromagnetic Compatibility of Technical Facilities - Norms for the Quality of Electric Power in GeneralPurpose Power Supply Systems") (In Russian). [online][16.03.2018] Available at: http://docs.cntd.ru/document/1200104301.

[8] EN 50160:2010 [online] [16.03.2018] Available at: http://www.cdtechnics.be/542-standard-en50160-voltage-characteristics-in.pdf. 